\title{
Development and validation of self-efficacy and intention measures for spending time in nature
}

\author{
Jay E. Maddock ${ }^{1,2^{*}}$, Courtney Suess ${ }^{3}$, Gregory N. Bratman ${ }^{4}$, Carissa Smock ${ }^{5}$, Debra Kellstedt ${ }^{6}$, Jeanette Gustat ${ }^{7}$, \\ Cynthia K. Perry ${ }^{8}$ and Andrew T. Kaczynski ${ }^{9}$
}

\begin{abstract}
Purpose: The purpose of this study was to develop and evaluate the reliability and validity of self-efficacy and intentions measures for time spent in nature (TSN). TSN is related to improvement in psychological well-being and health, yet most American adults spend very little time in such settings. Theory-based interventions have been effective in increasing physical activity, a related behavior, and may be one mechanism to increase TSN. Self-efficacy and intentions have been shown to be strong predictors of health behaviors and are used across several theories. However, scales to measure these factors have not yet been developed and are needed to facilitate effective interventions.
\end{abstract}

Methods: TSN self-efficacy and intentions scales were developed using a sequential nine-step procedure: identification of the domain and item generation; content validity; pre-testing of questions; sampling and survey administration; item reduction; extraction of factors; tests of dimensionality; tests of reliability; and tests of validity. The 14-member multidisciplinary, researcher and practitioner investigative team generated 50 unique items for self-efficacy and 24 unique items for intentions. After subjecting items to content validity and pre-testing, item sets were reduced to 21 assessing self-efficacy and nine assessing intentions. A nationwide sample of 2109 adult participants (49.7\% female, Mean Age $=58.1 ; 59.8 \%$ White, 18.4\% Hispanic, 13.3\% Black) answered these items via an on-line survey.

Results: Using split-half measures, principal components analysis indicated a one-factor solution for both scales. The factor structure was upheld in confirmatory factor analyses and had high internal consistency ( $a=.93$ self-efficacy; .91 intentions). The scales were moderately correlated with each other $(r=.56, p<.001)$ and were strongly related to TSN with large effect sizes (eta ${ }^{2}>$.20).

Conclusions: The study resulted in reliable and valid self-efficacy (14 items) and intentions ( 8 items) scales that can be used to develop future theory-based interventions to increase TSN and thereby improve population health.

Keywords: Social Cognitive Theory, Health promotion, Nature, United States

*Correspondence: maddock@tamu.edu

1 Department of Environmental and Occupational Health, School of Public Health, Texas A\&M University, 1266 TAMU, College Station, TX 77843, USA

Full list of author information is available at the end of the article

\section{Introduction}

Relationship of nature to health

A body of evidence from various disciplines has demonstrated the myriad ways in which nature contact is associated with physical and mental health [1-3]. These findings include investigations of visits to a variety of different types of nature, from urban greenspace to large forests outside of city limits, residential and community 
gardens, ocean beaches, coastlines, and many other environments [4-7]. Documented effects and associations range from cognitive restoration to reductions in stress, anxiety, and mental health disorders, improvements in emotion regulation, enhanced immune function, increased physical activity, and social cohesion [8-13]. Many questions remain, however, about causal mechanisms, the characteristics of the dose-response relationship with respect to specific outcomes, and the ways in which individual and population-level differences may moderate the impact of nature contact on health [14-18].

\section{Need for interventions to increase time spent in nature}

Despite the strength of this evidence and recent efforts to incorporate considerations of the health benefits of nature contact into urban planning, as well as increasing support for "green prescriptions" from some health care providers, most Americans spend less than five hours per week in nature [19]. As attention from diverse sectors turns to potential interventions that may increase nature contact, a variety of considerations must be taken into account. This includes further research into the factors that influence intentions and capability to visit natural spaces.

Connectedness to nature is a construct that is examined in a variety of different contexts within the literature, using the Connectedness to Nature Scale [20]; the Inclusion of Nature in Self Scale [21]; the Nature Relatedness Scale [22] and other measures. Increased feelings of connection to the natural world is found to be associated with well-being and pro-environmental behaviors (e.g., support for conservation) [23] and some evidence is emerging that this connection may predict frequency of nature contact as well [24]. Interventions that increase these feelings of relatedness and connectedness to the natural world may therefore have repercussions on intentions for future visitation to these environments. These types of motivations are likely to be related to intrinsic motivation for nature contact. This is an important factor to consider, as recent research has demonstrated the importance of accounting for intrinsic versus extrinsic motivation or perceived social pressure to visit nature, and how these differences may moderate the affective impacts of nature contact [25].

Despite feelings of connection to nature, however, significant obstacles exist for some individuals in the form of social, financial, and physical barriers to access [2631 ] and experiences of discrimination and lack of safety within these spaces [32-35]. These barriers to access and participation are very likely to adversely impact intentions to visit nature. Park design and maintenance, amenities, neighborhood characteristics, and provision of inclusive programming are also significant predictors of use and visitation [36-39]. Access to nature is therefore determined not only by physical distance and adequate infrastructure, but by capabilities that are highly influenced by social and economic factors as well [12, 40].

\section{Theoretical underpinnings}

Theory-based interventions are effective in changing a wide variety of health behaviors from smoking to physical activity and organ donation [41]. To date, interventions to increase time spent in nature are focused on increasing access to green space, physician-based prescriptions, and programmatic activities [42, 43]. The development of valid and reliable measures of theoretical constructs is an essential first step in developing theory-based interventions [44]. These and other studies demonstrate the need for developing valid and reliable psychosocial measures that support theory-based interventions to increase time spent in nature [2].

Self-efficacy and intentions are two of the most robust theoretical constructs in predicting behaviors. Selfefficacy was originally integrated into Social Cognitive Theory and is integrated into the Theory of Planned Behavior, Health Belief Model, and the Transtheoretical Model [45-47]. Intentions are the key construct in the Theory of Planned Behavior and the Theory of Reasoned Action. Fishbein positioned intentions as the main construct through which attitudes, norms and self-efficacy effect behaviors [48].

Self-efficacy includes perceived confidence to conduct a behavior successfully [45]. Influenced by individual capabilities and environmental factors, self-efficacy includes control over barriers as well as ability to perform a behavior [49]. Self-efficacy is shown to be one of the strongest predictors of intentions and behavior across a variety of studies [50, 51]. For example, Netz et al. found positive correlations between high levels of self-efficacy and performing physical activity, suggesting that perceived selfefficacy in ability to perform physical activity must be established before other motivational interventions are considered [52]. It is therefore probable that self-efficacy is necessary to increase spent time in nature; however, measures to determine this association are needed.

Intentions to perform a behavior are the most proximate measure to a health behavior [53]. Attitudes, norms, and self-efficacy have all been shown to influence intentions and, through changes in intentions, behavior [50,54]. The Theory of Planned Behavior posits that behavior is influenced directly through intentions which mediate all other pathways [53]. Therefore, measuring intentions to spend time in nature is critical as changes in self-efficacy, attitudes, and norms should directly influence intentions [55]. 


\section{Study aims}

The goals of this study were to develop reliable and valid scales for self-efficacy and intentions to spend time in nature.

\section{Methods \\ Design}

The TSN self -efficacy and intentions scales were developed using the sequential methods developed by Jackson [56] and Comrey [57] and expanded on by Boateng et al. [58]. These methods follow a nine-step procedure: (1) identification of the domain and item generation; (2) examination of content validity; (3) pre-testing of questions; (4) sampling and survey administration; (5) item reduction; (6) extraction of factors; (7) tests of dimensionality; (8) tests of reliability; and (9) tests of validity. Figure 1 provides a pictorial representation of these study stages.

In phase one, self-efficacy was defined as a person's confidence in his or her ability to take action and to persist in that action despite obstacles or challenges pertaining to spending time in nature. Intentions were defined as planning to engage in certain nature-related behaviors over the next three months. The 14-member multidisciplinary, researcher and practitioner, international investigative team individually generated items about self-efficacy and intentions to spend time in nature based on these prompts. For example, the intentions prompt was, "In the next three months, do you intend to..." The lead investigator reviewed all generated items and eliminated duplicates. In phase two, all items were reviewed and rated individually by the investigative team using a Qualtrics survey. Items were first rated on how relevant they were to the construct of self-efficacy or intentions on a four-point Likert scale ranging from not relevant to very relevant. Next, thematic subsets were rank ordered based on their importance to spending time in nature. Items that had means of less than 2.5 on relevance and scored in the bottom quartile of importance were removed.

In phase three, several members of the research team recruited community members across the country to participate in pretesting of items using a cognitive interview. A research team member sat with an individual as they read the questions and took item-by-item feedback for items that were confusing, double barreled, or otherwise difficult to answer [44]. Poorly preforming items were again eliminated during this phase of the study.

In phase four, a nationwide sample of participants was acquired through a panel from Qualtrics of United States (U.S.) adult residents aged 18 or older. There is some disagreement on the sample size needed for factor analysis ranging from 5 to 10 respondents per item to 100 to 1000 respondents per study. Comrey [57] has rated a sample size of 1000 as excellent for factor analysis stability. Since this study was using split-half methods, a sample of 2000 was planned. Respondents included in the Qualtrics database were self-selected to be part of the present study. To minimize self-selection bias, Qualtrics sends a survey invitation to its panel members without disclosing the particular topic so that respondents participate in the survey without knowing the nature of the survey beforehand, effectively facilitating a more random sampling procedure. Data collection was completed over a one-month period (June 23-July 21, 2021) and respondents were stratified by age, gender, and region within the U.S. to be nationally representative of those characteristics. Participants were presented with an informed consent informational sheet prior to receiving the survey and indicated their consent electronically. The survey was soft launched with 200 participants to ensure all questions were answered and that there were no issues with

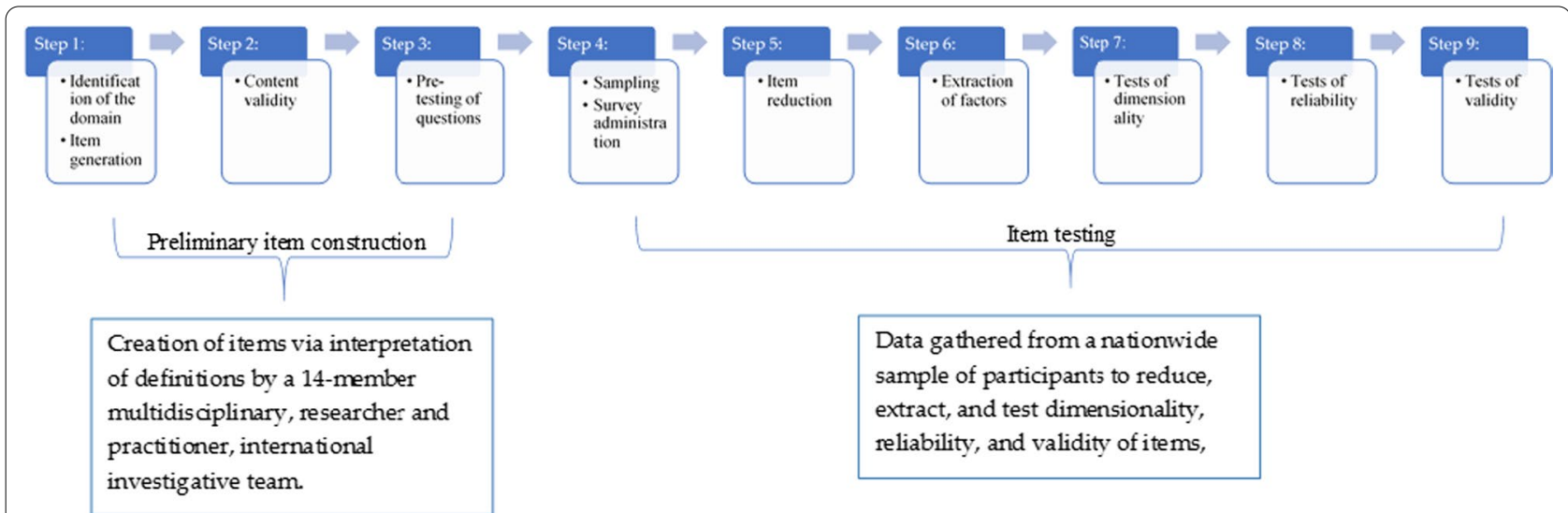

Fig. 1 Pictorial representation of methodology steps 
the survey programming. As a quality check, participants who completed the study in less than half the soft launch mean time $(12.5 \mathrm{~min})$ were removed from the sample to eliminate participants that were not responding thoughtfully. On average, the survey took $29.4 \mathrm{~min}$ to complete. All study procedures were conducted according to the World Medical Association Declaration of Helsinki and to conform to the ICMJE Recommendations for the Conduct, Reporting, Editing, and Publication of Scholarly Work in Medical Journals. All study procedures were approved by the Texas A\&M University Institutional Review Board.

\section{Materials/measures}

Instrument content includes questions to assess time spent in nature, social cognitive measures, attitudes and behavioral capacity, and demographics. When possible, questions were formatted following the same structure and adapted from validated instruments.

\section{Time spent in nature}

Two questions were used to assess time spent in nature. The first question measured the frequency of visits to natural areas. It was adapted from the People and Nature Survey for England-Adults [59]. The question described what types of nature spaces are included and asked, "In the past 12 months, how often, on average have you spent free time outside in green and natural spaces?" Response options included: every day, more than twice a week but not every day, twice a week, once a week, once or twice a month, once every 2-3 months, less often, and never. Some minor changes in the examples were made to increase readability among Americans audiences (e.g., forests for woodlands). The second question, which measures duration rather than frequency, was taken verbatim from the Nature of Americans study [19]. The question asks, "In the typical week, when the weather allows, about how long on average do you spend outdoors in nature?" Response choices included: none, some but less than $30 \mathrm{~min}, 30 \mathrm{~min}$ to an hour, $1-2 \mathrm{~h}, 2-3 \mathrm{~h}$, 3-4 h, 4-5 h, 5-7 h, and more than $7 \mathrm{~h}$. Both of these aspects of nature exposure are informative to assess, as some research has found frequency and duration to be associated with different outcomes [60].

\section{Social cognitive measures}

The self-efficacy questions all started with the stem: "How confident are you right now that you could spend at least two hours per week in green or natural spaces if...." Response options included: not at all confident, slightly confident, somewhat confident, very confident, and extremely confident. Intention items started with the stem: "In the next three months, do you intend to...."
Response options included: strongly disagree, disagree, neither agree nor disagree, agree, and strongly agree.

\section{Attitudes and behavioral capacity}

Additional scales were included to provide convergent validity for self-efficacy and intentions. These included an Attitudes towards Spending Time in Nature scale, which contains three factors: positive attitudes, negative attitudes, and concerns about spending time in nature [61]. A single factor scale measuring behavioral capacity to spend time in nature was also included [62].

\section{Socio-demographics}

Socio-demographic questions assessed included age, gender, race and ethnicity, marital status, education, income, state of residence, zip code, general health, and the ability to walk for more than $10 \mathrm{~min}$.

\section{Participants}

In the survey portion of the study, 4414 people clicked on the link to the study. Of these, 3847 provided informed consent and 3120 answered any questions. Overall, 2109 participants (67.6\% of those that started) completed the survey and passed the quality check. The participants identified as male (49.6\%), female (49.7\%), and nonbinary $(0.7 \%)$. The median age was 58.1 years $(\mathrm{SD}=17.1)$. The sample was ethnically diverse with $59.8 \%$ white respondents, $18.4 \%$ Hispanic, $13.3 \%$ Black, and $8.0 \%$ mixed and other. Median income was \$50,000-59,999 and just over half of the sample was married (51.2\%). Education was well distributed with $47.4 \%$ having less than a college degree, $35.2 \%$ having a two- or four-year college degree, and $17.5 \%$ having an advanced degree. Respondents came from all 50 states, Puerto Rico, and D.C. Most respondents (74.5\%) were in good to excellent health and could walk $10 \mathrm{~min}(87.5 \%)$ without assistance. The sample had a fairly high level of frequency of exposure to nature with $30.5 \%$ going into natural spaces every day, $28.8 \%$ more than twice per week, and $16.0 \%$ less than once per month. Duration of time spent in nature was less, with $47.3 \%$ spending less than an hour per week in nature and $22.3 \%$ spending one to two hours per week. Only $30.4 \%$ met the recommended threshold of spending two or more hours per week in nature. Table 1 presents the sample demographics.

\section{Data analyses}

In phase five of the study, we conducted item analysis. Survey items with correlations of $>.70$ with another item were removed to reduce collinearity. Items with extreme distribution characteristics, such as a non-central mean, restriction in range, skewness, and kurtosis, were identified and eliminated. 
Table 1 Sample demographics $(n=2109)$

\begin{tabular}{|c|c|}
\hline Variable & $M(S D)$ or $\%$ \\
\hline Gender (\% Female) & 49.7 \\
\hline Age & $58.1(17.1)$ \\
\hline \multicolumn{2}{|l|}{ Education } \\
\hline High school or less & 21.7 \\
\hline Some or community college & 36.8 \\
\hline Bachelor's degree & 24.1 \\
\hline Graduate or professional degree & 17.5 \\
\hline \multicolumn{2}{|l|}{ Household income } \\
\hline Less than $\$ 30,000$ & 27.7 \\
\hline$\$ 30,000-\$ 49,999$ & 21.5 \\
\hline$\$ 50,000-\$ 69,999$ & 16.6 \\
\hline$\$ 70,000-\$ 99,999$ & 16.9 \\
\hline$\$ 100,000+$ & 17.3 \\
\hline \multicolumn{2}{|l|}{ Race/ethnicity } \\
\hline White, non-Hispanic & 59.8 \\
\hline Black, non-Hispanic & 13.3 \\
\hline Hispanic & 18.4 \\
\hline Other & 8.0 \\
\hline \multicolumn{2}{|l|}{ General health } \\
\hline Excellent & 15.9 \\
\hline Good & 58.6 \\
\hline Fair & 22.1 \\
\hline Poor & 3.4 \\
\hline \multicolumn{2}{|c|}{$\begin{array}{l}\text { In the typical week, when the weather allows, about how long on aver- } \\
\text { age do you spend outdoors in nature? }\end{array}$} \\
\hline None & 5.5 \\
\hline Some but less than $30 \mathrm{~min}$ & 16.8 \\
\hline 30 min to an hour & 25.0 \\
\hline $1-2 h$ & 22.3 \\
\hline $2-3 h$ & 11.0 \\
\hline $3-4 h$ & 6.4 \\
\hline $4-5 h$ & 5.5 \\
\hline $5-6 h$ & 3.0 \\
\hline More than $7 \mathrm{~h}$ & 4.6 \\
\hline \multicolumn{2}{|c|}{$\begin{array}{l}\text { In the last } 12 \text { months, how often, on average have you spent your free } \\
\text { time outside in green and natural spaces? }\end{array}$} \\
\hline Every day & 30.5 \\
\hline More than twice a week, but not everyday & 28.8 \\
\hline Twice a week & 8.8 \\
\hline Once a week & 9.3 \\
\hline Once or twice a month & 6.6 \\
\hline Once every 2-3 months & 2.5 \\
\hline Less often & 4.9 \\
\hline Almost never & 8.6 \\
\hline
\end{tabular}

In phase six, the factor dimensionality of the scales was examined. To facilitate both exploratory and confirmatory analyses, we used the split-half procedure, in which the sample was randomly divided in half. The first half of the sample was selected for exploratory analysis. An exploratory principal components analysis (PCA) was conducted on the matrix of item intercorrelations generated from the first half of the sample using pair-wise deletion. The number of components retained was determined by comparing the results of two procedures (scree procedure and parallel analysis method) that have been shown to be valid predictors of the correct dimensionally of an item set [63]. In some cases, the scree procedure [64] may over extract factors, and for this reason the Parallel Analysis tables developed by Lautenschlager [65] were also used [66]. Orthogonal (varimax) rotations were examined. Items loading less than 0.50 on a factor were removed. Items loading $>0.30$ on multiple factors were also removed to reduce collinearity across the subscales.

In phase seven, following the PCA conducted on the first half of the data, confirmatory factor analysis (CFA) was performed on the other half of the data to evaluate the latent structure and provide support for construct validation CFA provides a rigorous test of the proposed scales through testing how well the measures' variables or items represent the constructs [67]. Indicators were specified and parameters estimated with a maximum likelihood technique using STATA 15.0. Evaluation of a CFA requires an assessment of overall fit to the data [68]. In phase seven CFA was conducted to establish convergent validity through the common variance the items on the construct shared with the latent construct. Hair et al. [68] recommends all factor loadings should be statistically significant with loadings of at least 0.50 or higher to represent convergent validity. Fornell et al. [69] indicates parameter estimates 0.70 or higher are considered acceptable where the amount of information shared with a latent construct is greater than the error variance. Further, the CFA allows for measurement of average variance extracted (AVE). Hair et al. [68] suggests that AVE should be above .50. Reliability is the third criterion of convergent validity, Joerskog Rho indicates construct reliability; values higher than 0.7 indicate internal consistency, which represents all of the items of the scale consistently measuring the same latent construct [68].

In phase eight, reliability of scales was measured using Cronbach's alpha. In general, an alpha $>.70$ is considered to be a good measure of internal consistency [70]. If the overall alpha was below .70, individual items were examined to assess if removing the item would increase the overall alpha of the scale. In phase nine to test criterion validity, the relationships between self-efficacy, intentions, and time spent in nature were examined using one-way ANOVAs. 


\section{Results}

In phase one, the research team generated 50 unique items for self-efficacy and 24 unique items for intentions. In phase two, the item set for self-efficacy was reduced to 32 items and intentions was reduced to 12 items. Twelve participants pre-tested items during cognitive interviews (phase three) and were diverse in gender, race and ethnicity, geography, age, and educational attainment. The pre-testing phase further reduced the self-efficacy set to 21 items and the intentions set to nine items.

After conducting the national survey, item quality was assessed. All self-efficacy items had good variance and were retained. In bivariate correlations, two items ("you feel stress" and "you feel depressed") had a correlation of .715 and two additional items ("you are busy" and "you have a lot of work to do") had a correlation of .707. The items with less variance and higher skewness ("you feel depressed" and "you have a lot of work to do") and were removed. All other items had correlations less than .70 with the other items. Next, items were assessed relative to the amount of time spent in nature. Five items had small relationships with time spent in nature and were removed resulting in 14 retained items. All intentions items had good variance and were retained. In bivariate correlations, two items (spend more time outside and spent more time in nature) a correlation of .721. Spend more time outside had less variance and higher skewness and was removed leaving 8 items.

In phase six, the PCA was assessed on a randomly selected first half of the sample $(n=1607)$. Eigenvalues for two factors were greater than one $(7.69,1.13)$ indicating two factors using the Scree procedure [64] and one using Lautenschlager's tables [65]. Both solutions were investigated. The two-factor solution had several items load on both factors and was uninterpretable. The one factor solution had all items load $>0.60$ accounting for $54.9 \%$ of the variance. Intentions had only one eigenvalue greater than one (4.82) indicating a one factor solution for both factor extraction methods. All items loaded higher than 0.60 and the factor accounted for $60.3 \%$ of the variance.

In phase seven, convergent validity was established by the CFA. Standardized loadings for items measuring self-efficacy ranged from .616 to .779 and were significant $(p<.001)$. Further, the CFA demonstrated that the average variance extracted (AVE) from items was .513 , above the threshold suggested by Hair et al. (2010), further demonstrating convergent validity. Reliability was the third criterion of convergent validity assessed. The Joreskog Rho construct reliability [68] was .913. A score higher than 0.7 indicates internal consistency, which represents all of the items of the scale consistently measuring the same latent construct [68]. Following the
CFA, fit statistics were assessed and model testing indicated an adequate fit to the data (CFI $=.906$, TLI $=.889$, $\mathrm{SRMR}=.051$, RMSEA $=.097)$. These data can be found in Table 2. The items measuring intentions ranged from .673 to .814 and were significant $(p<.001)$. The AVE was .537 , indicating convergent validity, and the Rho was .902 demonstrating construct reliability. The tests for goodness of fit indicated model achieved a mediocre fit to the data $(\mathrm{CFI}=.914, \mathrm{TLI}=.880, \mathrm{SRMR}=.053$, RMSEA = .135).

In phase eight, Cronbach's alpha for self-efficacy was 0.93 and 0.91 for intentions. The correlation between the two scales was $0.56(p<.001)$. In phase nine, both scales showed significant differences and eta-squares $>.20$ indicating large effect sizes across frequency and time spent outside. These results are displayed in Tables 3 and 4 . Convergent and divergent validity with demographics, behavioral capacity, and attitudes towards spending time in nature were then assessed. Self-efficacy and intentions were moderately correlated $(\mathrm{r}=.56, p<.001)$. Self-efficacy was significantly, positively correlated with positive attitudes towards spending time in nature $(\mathrm{r}=.40, p<.001)$ and behavioral capacity $(\mathrm{r}=.51, p<.001)$ and negatively correlated with negative attitudes towards spending time in nature $(\mathrm{r}=-.17)$, concerns about spending time in nature $(-.28, p<.001)$, and age $(-.07, p<.001)$. Intentions were significantly, positively correlated with positive attitudes $(\mathrm{r}=.58, p<.001)$ and behavioral capacity $(\mathrm{r}=.56, p<.001)$ and negatively correlated with negative attitudes $(\mathrm{r}=-.24, p<.001)$, concerns about nature $(-.19, p<.001)$, and age $(-.16, p<.001)$. Males reported significantly higher self-efficacy scores than women. However, there were no gender differences on intentions. For race/ethnicity, there were no differences on self-efficacy. For intentions, Hispanic participants scored significantly higher than both Black and White respondents. Both scales were significantly related to general health, with participants in excellent and good health reporting higher levels than those in fair and poor health. These results are displayed in Table 5.

\section{Discussion}

The goal of this study was to develop reliable and valid measures for self-efficacy and intentions to spend time in nature. Having a better understanding of cognitive factors that are associated with individuals spending time in nature will support health promotion and evaluation efforts. The study followed gold standard guidelines proposed by Boateng et al. [58]. For both scales, a one-factor solution was found that was validated in a confirmatory factor analysis. Both scales had excellent levels of internal consistency. The scales were moderately correlated with each other and had a strong relationship with TSN. 
Table 2 Confirmatory factor analysis results

\begin{tabular}{|c|c|c|c|}
\hline Constructs and measurement item & Standardized loading ${ }^{\text {ad }}$ & Error variance $^{b}$ & $\begin{array}{l}\text { Indicator } \\
\text { reliability }\end{array}$ \\
\hline \multicolumn{4}{|l|}{ First-order loadings } \\
\hline \multicolumn{4}{|l|}{ Self-efficacy $(a=.919 ; \rho=.933 ; \mathrm{AVE}=.584)^{c}$} \\
\hline It is really hot outside & .72 & .012 & .518 \\
\hline It is really cold outside & 69 & .012 & .476 \\
\hline It is raining or snowing & .68 & .012 & .462 \\
\hline Daylight hours are shorter & .74 & .011 & .548 \\
\hline You are busy & .75 & .010 & .563 \\
\hline You feel stressed & .73 & .011 & .533 \\
\hline Nature is far away & .70 & .012 & .490 \\
\hline You feel tired & .78 & .010 & .608 \\
\hline There are no people around & .65 & .014 & .423 \\
\hline You have no one to go with & .72 & .011 & .518 \\
\hline You are in pain & .72 & .011 & .518 \\
\hline You lack transportation to natural areas & .68 & .012 & .462 \\
\hline It feels unsafe & .62 & .014 & .384 \\
\hline There is an expense involved (like a park pass or entrance fee) & .62 & .014 & .384 \\
\hline \multicolumn{4}{|l|}{ Intentions $(a=.91 ; \rho=.90 ; \mathrm{AVE}=.54)^{\mathrm{c}}$} \\
\hline Spend more time at neighborhood and community parks & .70 & .012 & .490 \\
\hline Spend at least two hours per week outside & .67 & .013 & .449 \\
\hline Visit state or national parks & .76 & .010 & .578 \\
\hline Schedule trips to natural areas & .81 & .009 & .656 \\
\hline Go on a hike & .73 & .012 & .533 \\
\hline Go on a walk outdoors & .68 & .013 & .462 \\
\hline Visit water recreation areas (i.e. lakes, oceans) & .71 & .012 & .504 \\
\hline Spend more time in nature & .79 & .010 & .624 \\
\hline
\end{tabular}

${ }^{a}$ Entries are standardized values; all statistically significant $(p<.01)$

${ }^{\mathrm{b}}$ Error variance entries are standardized

${ }^{c} a=$ Cronbach's alpha of reliability; $\rho=$ composite construct reliability; AVE = amount of variance extracted. The average variance estimates (AVEs) ranged between 0.591 and 0.821

d Values exceeded the 3.26 cutoff

Table 3 One-way ANOVA of self-efficacy and intentions by frequency of visits to natural spaces

\begin{tabular}{|c|c|c|}
\hline \multirow[t]{3}{*}{ Frequency of visits to natural areas and greenspaces } & \multirow{3}{*}{$\begin{array}{l}\text { Self-efficacy } \\
F(7,2060)=57.3, p<.001, \eta^{2}=0.22 \\
M(S D)\end{array}$} & \multirow{3}{*}{$\begin{array}{l}\text { Intentions } \\
F(7,2090)=127.3, \\
p<.001, \eta^{2}=0.30 \\
M(S D)\end{array}$} \\
\hline & & \\
\hline & & \\
\hline Almost never & $1.79(0.81)$ & $2.13(0.97)$ \\
\hline Less than every 2-3 months & $2.16(0.80)$ & $2.61(0.87)$ \\
\hline Once every $2-3$ months & $2.13(0.77)$ & $3.09(0.93)$ \\
\hline Once or twice a month & $2.28(0.74)$ & $3.19(0.76)$ \\
\hline Once a week & $2.37(0.78)$ & $3.34(0.83)$ \\
\hline Twice a week & $2.66(0.77)$ & $3.59(0.75)$ \\
\hline More than twice a week, but not everyday & $2.83(0.82)$ & $3.73(0.80)$ \\
\hline Everyday & $3.20(0.90)$ & $3.92(0.78)$ \\
\hline
\end{tabular}


Table 4 One-way ANOVA of self-efficacy and intentions by times per week spent in natural spaces

\begin{tabular}{|c|c|c|}
\hline \multirow{3}{*}{$\begin{array}{l}\text { Time per week in natural } \\
\text { areas and greenspaces }\end{array}$} & \multirow{2}{*}{$\begin{array}{l}\text { Self-efficacy } \\
F(8,2057)=49.8 \\
p<.001, \eta^{2}=0.22\end{array}$} & \multirow{2}{*}{$\begin{array}{l}\text { Intentions } \\
F(8,2087)=71.9, \\
p<.001, \eta^{2}=0.25\end{array}$} \\
\hline & & \\
\hline & $M(S D)$ & $M(S D)$ \\
\hline None & $1.75(0.84)$ & $2.14(1.07)$ \\
\hline Some but less than 30 min & $2.14(0.77)$ & $2.86(0.92)$ \\
\hline 30 min to an hour & $2.60(0.81)$ & $3.53(0.86)$ \\
\hline $1-2 h$ & $2.83(0.85)$ & $3.70(0.77)$ \\
\hline $2-3 h$ & $3.08(0.82)$ & $3.82(0.77)$ \\
\hline $3-4 h$ & $3.17(0.89)$ & $3.91(0.82)$ \\
\hline $4-5 h$ & $3.32(0.89)$ & $3.90(0.75)$ \\
\hline $5-7 h$ & $3.21(0.87)$ & $4.07(0.65)$ \\
\hline More than $7 \mathrm{~h}$ & $3.45(0.91)$ & $4.08(0.82)$ \\
\hline
\end{tabular}

Implications for measuring the relationship of nature to health based on these findings include important insights into the ways in which perceived affective responses to time in nature may impact propensity for frequency and duration of exposure to natural spaces. In general, total duration of exposure was positively associated with both self-efficacy and intentions to spend time in nature. Thus, recommendations for developing interventions to increase time spent in nature based on findings from this study include a focus on measuring and increasing confidence to spend time in nature in a variety of situations while also addressing intentions to spend time in a variety of greenspaces. Strategies will therefore include a variety of different approaches, depending upon the specific aspects that are the focus of an intervention. A systematic review and meta-analysis found that successful strategies to increase self-efficacy for physical activity included: action planning, time management, prompt self-monitoring of behavioral outcomes, and planning social support and social change [71]. For example, increasing self-efficacy in nature may be accomplished through observation learning or guided experiences that increase connectedness to nature or sense of place, while intentions might be effectively increased through goal setting, planning, addressing barriers and consciousness raising [72].

There were several interesting findings related to the scales and demographics. While nature exposure is shown to be beneficial to healthy aging, both selfefficacy and intentions were negatively correlated with age [73]. Older adults may have mobility or safety concerns that reduce their intentions and self-efficacy for spending time in nature. In the U.S., less than $10 \%$ of park users are older adults and may benefit from parks constructed with older adults in mind [74, 75]. Similar findings were found for general health, with healthier people reporting higher intentions and self-efficacy. For gender, while there was no difference in intentions, males reported higher self-efficacy. A recent study found that although females reported being more connected to nature and preferred outdoor environments for recreation, they were less likely to participate in nature-based recreation [24]. This may be due in part to a difference in self efficacy. Racial and ethnic differences were limited; for self-efficacy no differences were found and intentions were only higher for Hispanic

Table 5 Convergent and divergent validity of self-efficacy and intentions scales

\begin{tabular}{|c|c|c|}
\hline Gender & $\begin{array}{l}\text { Self-efficacy } \\
t(2041)=7.16, p<.001, d=.32 \\
M(S D)\end{array}$ & $\begin{array}{l}\text { Intentions } \\
t(2071)=0.76, n . s \\
M(S D)\end{array}$ \\
\hline Males & $2.86(0.96)$ & $3.52(0.96)$ \\
\hline Females & $2.56(0.89)$ & $3.48(0.89)$ \\
\hline Race/Ethnicity & $F(3,2003)=1.2, n \cdot s$ & $F(3,2032)=8.2, p<.001, \eta^{2}=0.01$ \\
\hline White, non-Hispanic & $2.68(0.94)$ & $3.44(0.90)$ \\
\hline Black & $2.75(0.94)$ & $3.46(0.99)$ \\
\hline Hispanic & $2.78(0.90)$ & $3.73(0.92)^{1}$ \\
\hline Other & $2.68(0.99)$ & $3.55(0.90)$ \\
\hline General health & $F(3,2058)=88.1, p<.001, \eta^{2}=0.11$ & $F(3,2088)=58.8, p<.001, \eta^{2}=0.08$ \\
\hline Excellent & $3.28(0.98)^{2}$ & $3.90(0.86)^{2}$ \\
\hline Good & $2.74(0.88)$ & $3.55(0.90)$ \\
\hline Fair & $2.33(0.84)$ & $3.16(1.00)$ \\
\hline Poor & $1.98(0.81)$ & $2.73(1.20)$ \\
\hline
\end{tabular}

\footnotetext{
${ }^{1}$ Hispanic participants scored significantly higher than White and Black participants, Tukey HSD
}

${ }^{2}$ All groups are significantly different from each other, Tukey HSD 
respondents. While more research into this is needed, Taylor [76] likewise found little differences in racial and ethnic groups on connectedness to nature and landscape preferences.

Positive attitudes towards spending time in nature were strongly related to intentions, while negative attitudes and concerns about nature had smaller relationships. While self-efficacy also had a strong relationship with positive attitudes, concerns about being in nature were also correlated. This provides preliminary insight into the value of increasing positive attitudes while providing strategies to address concerns about nature. Negative attitudes seem to play less of a role in intentions or self-efficacy. This is in line with behavioral capacity which was strongly related to both scales and may be a tangible pathway to improve self-efficacy and intentions [72].

Over the past few years, interventions to increase time in nature have become more popular. However, these have been based on adding plants and gardens to indoor and urban areas, physician recommendations for nature contact (e.g. ParkRX), or place-based programming (e.g. community gardens) [43,60]. To date, there is a lack of theory-based behavioral change interventions focused on individuals, families, or other social groups. This study offers progress toward the provision of measures that will serve as the foundation for interventions about self-efficacy and intentions to spend time in nature. The resulting reduction in items based on factor loadings further created succinct and user-friendly measures that can be applied across a variety of academic and practical contexts.

This study has several limitations. While the sample came from across the United States and was representative of the US population on gender and race, the average age of the respondents tended to be older than the population median. Since the survey was collected via the internet, no validation of time spent in nature was possible but the study did use validated measures of nature exposure from the United States and the United Kingdom. With an internet-based study, people without internet access or the ability to read and write in English were excluded. The self-efficacy scale does differ a bit from Bandura's [77] recommendations which included using a 10-point Likert scale and using responses worded as certainty rather than confidence. However, in the health promotion literature, most self-efficacy scales have used a 5-point Likert scale with confidence as the prompts [78, 79].

In conclusion, this study resulted in reliable and valid measures of self-efficacy and intentions to spend time in nature. The measures will be helpful in developing and evaluating theory-based interventions to increase time in nature.

\section{Acknowledgements}

This research was conducted in partnership with the Physical Activity Policy Research Evaluation Network Parks \& Greenspace workgroup. We would like to thank David Brown, Russ Carson, Teresa Horton, Robby Layton, Teresa Penbrooke, and Elsa Pérez-Paredes for their contribution to the study.

\section{Authors' contributions}

$J M$ conceptualized and led the study. JM and CS ran the statical analyses. JM, CS, GB, CS, DK, JG, CP, and AK contributed to data collection, participated in writing sections of the paper, and reviewed the manuscript. All authors read and approved the final manuscript.

\section{Funding}

This study was funded by a gift from the Marek Family to the Center for Health and Nature.

\section{Availability of data and materials}

The data and scales are available by contacting the corresponding author.

\section{Declarations}

\section{Ethics approval and consent to participate}

All study protocols were carried out in accordance with relevant guidelines and regulations and were approved by the Texas A\&M University Institutional Review board. Informed consent was obtained from all subjects.

\section{Consent for publication}

Not applicable.

\section{Competing interests}

The authors have no competing interests as defined by BMC, or other interests that might be perceived to influence the results and/or discussion reported in this paper.

\section{Author details}

${ }^{1}$ Department of Environmental and Occupational Health, School of Public Health, Texas A\&M University, 1266 TAMU, College Station, TX 77843, USA. ${ }^{2}$ Center for Health and Nature, Houston Methodist Research Institute, Houston, TX, USA. ${ }^{3}$ Department of Recreation, Park and Tourism Sciences, Texas A\&M University, College Station, TX, USA. ${ }^{4}$ School of Environmental and Forest Sciences, University of Washington, Seattle, WA, USA. ${ }^{5}$ School of Business, Northcentral University, San Diego, CA, USA. ${ }^{6}$ Texas A\&M AgriLife Extension, College Station, TX, USA. ${ }^{7}$ Department of Epidemiology, Tulane University, New Orleans, LA, USA. ${ }^{8}$ School of Nursing, Oregon Health and Sciences University, Portland, OR, USA. ${ }^{9}$ Department of Health Promotion, Education, and Behavior, University of South Carolina, Columbia, SC, USA.

Received: 30 November 2021 Accepted: 22 February 2022

Published online: 03 March 2022

References

1. Bratman GN, Anderson CB, Berman MG, Cochran B, de Vries S, Flanders J, Folke C, Frumkin H, Gross JJ, Hartig T, Kahn PH, Kuo M, Lawler JJ, Levin PS, Lindahl T, Meyer-Lindenberg A, Mitchell R, Ouyang Z, Roe J, Scarlett L, Smith JR, van den Bosch M, Wheeler BW, White MP, Zheng H, Daily GC. Nature and mental health: an ecosystem service perspective. Sci Adv. 2019;5(7):eaax0903. https://doi.org/10.1126/sciadv.aax0903.

2. Frumkin H, Bratman GN, Breslow SJ, Cochran B, Kahn PH, Lawler JJ, Levin PS, Tandon PS, Varanasi U, Wolf KL, Wood SA. Nature contact and human health: a research agenda. Environ Health Perspect. 2017. https://doi.org/ 10.1289/EHP1663.

3. Christiana RW, Besenyi GM, Gustat J, Horton TH, Penbrooke TL, Shultz CL. A scoping review of the health benefits of nature-based physical activity. J Healthy Eat Act Living. 2021;1(3):127-60.

4. Jarvis I, Gergel S, Koehoorn M, van den Bosch M. Greenspace access does not correspond to nature exposure: measures of urban natural space with implications for health research. Landsc Urban Plan. 
2020;194:103686-103686. https://doi.org/10.1016/j.landurbplan.2019. 103686.

5. Marselle MR, Irvine KN, Lorenzo-Arribas A, Warber SL. Moving beyond green: exploring the relationship of environment type and indicators of perceived environmental quality on emotional well-being following group walks. Int J Environ Res Public Health. 2015;12(1):106-30. https:// doi.org/10.3390/ijerph120100106.

6. White MP, Elliott LR, Gascon M, Roberts B, Fleming LE. Blue space, health and well-being: a narrative overview and synthesis of potential benefits. Environ Res. 2020;191(September):110169-110169. https://doi.org/10. 1016/j.envres.2020.110169.

7. Wyles KJ, White MP, Hattam C, Pahl S, King H, Austen M. Are some natural environments more psychologically beneficial than others? The importance of type and quality on connectedness to nature and psychological restoration. Environ Behav. 2019;51(2):111-43. https://doi.org/10.1177/ 0013916517738312

8. Bratman GN, Young G, Mehta A, Lee Babineaux I, Daily GC, Gross JJ. Affective benefits of nature contact: the role of rumination. Front Psychol. 2021. https://doi.org/10.3389/fpsyg.2021.643866.

9. Fong $\mathrm{KC}$, Hart JE, James P. A review of epidemiologic studies on greenness and health: updated literature through 2017. Curr Environ Health Rep. 2018;5(1):77. https://doi.org/10.1007/s40572-018-0179-y.

10. Jennings $V$, Bamkole $O$. The relationship between social cohesion and urban green space: an avenue for health promotion. Int J Environ Res Public Health. 2019;16(3):452-452. https://doi.org/10.3390/ijerph1603 0452.

11. Kuo M. How might contact with nature promote human health? Promising mechanisms and a possible central pathway. Front Psychol. 2015;6(August):1-8. https://doi.org/10.3389/fpsyg.2015.01093.

12. Remme RP, Frumkin H, Guerry AD, King AC, Mandle L, Sarabu C, Bratman GN, Giles-Corti B, Hamel P, Han B. An ecosystem service perspective on urban nature, physical activity, and health. Proc Natl Acad Sci. 2021;118(22):e2018472118.

13. Wen Y, Yan Q, Pan Y, Gu X, Liu Y. Medical empirical research on forest bathing (Shinrin-yoku): a systematic review. Environ Health Prev Med. 2019. https://doi.org/10.1186/s12199-019-0822-8.

14. Bratman GN, Olvera-Alvarez HA, Gross JJ. The affective benefits of nature exposure. Soc Personal Psychol Compass. 2021. https://doi.org/10.1111/ spc3.12630.

15. Markevych I, Schoierer J, Hartig T, Chudnovsky A, Hystad P, Dzhambov AM, deVries S, Triguero-Mas M, Brauer M, Nieuwenhuijsen MJ, Lupp G, Richardson EA, Astell-Burt T, Dimitrova D, Feng X, Sadeh M, Standl M, Heinrich J, Fuertes E. Exploring pathways linking greenspace to health: theoretical and methodological guidance. Environ Res. 2017;158:301-17. https://doi.org/10.1016/j.envres.2017.06.028.

16. Marselle MR, Hartig T, Cox DTC, de Bell S, Knapp S, Lindley S, Triguero-Mas M, Böhning-Gaese K, Braubach M, Cook PA, de Vries S, Heintz-Buschart A, Hofmann M, Irvine KN, Kabisch N, Kolek F, Kraemer R, Markevych I, Martens D, Müller R, Nieuwenhuijsen M, Potts JM, Stadler J, Walton S, Warber SL, Bonn A. Pathways linking biodiversity to human health: a conceptual framework. Environ Int. 2021. https://doi.org/10.1016/j.envint. 2021.106420.

17. Shanahan DF, Bush R, Gaston KJ, Lin BB, Dean J, Barber E, Fuller RA. Health benefits from nature experiences depend on dose. Sci Rep. 2016:6(1):28551-28551. https://doi.org/10.1038/srep28551.

18. White MP, Alcock I, Grellier J, Wheeler BW, Hartig T, Warber SL, Bone A, Depledge MH, Fleming LE. Spending at least 120 minutes a week in nature is associated with good health and wellbeing. Sci Rep. 2019;9(1):1-11. https://doi.org/10.1038/s41598-019-44097-3.

19. Kellert SR, Case DJ, Escher D, Witter DJ, Mikels-Carrasco J, Seng PT. The Nature of Americans: National Report. 2017. https://natureofamericans. org/sites/default/files/reports/Nature-of-Americans_National_Report_ 1.3_4-26-17.pdf.

20. Mayer FS, Frantz CM. The connectedness to nature scale: A measure of individuals'feeling in community with nature. J Environ Psychol. 2004;24(4):503-15.

21. Schultz PW. The structure of environmental concern: concern for self, other people, and the biosphere. J Environ Psychol. 2001;21(4):327-39.

22. Nisbet EK, Zelenski JM, Murphy SA. The nature relatedness scale: Linking individuals' connection with nature to environmental concern and behavior. Environ Behav. 2009;41(5):715-40.
23. Pritchard A, Richardson M, Sheffield D, McEwan K. The relationship between nature connectedness and eudaimonic well-being: a metaanalysis. J Happiness Stud. 2020;21(3):1145-67.

24. Rosa CD, Larson LR, Collado S, Cloutier S, Profice CC. Gender differences in connection to nature, outdoor preferences, and nature-based recreation among college students in Brazil and the United States. Leis Sci. 2020;1-21.

25. Tester-Jones M, White MP, Elliott LR, Weinstein N, Grellier J, Economou T, Bratman GN, Cleary A, Gascon M, Korpela KM, Nieuwenhuijsen M, O'Connor A, Ojala A, van den Bosch M, Fleming LE. Results from an 18 country cross-sectional study examining experiences of nature for people with common mental health disorders. Sci Rep. 2020;10(1):19408. https://doi.org/10.1038/s41598-020-75825-9.

26. Ekkel ED, de Vries S. Nearby green space and human health: Evaluating accessibility metrics. Landsc Urban Plan. 2017;157:214-20.

27. Byrne J. When green is White: the cultural politics of race, nature and social exclusion in a Los Angeles urban national park. Geoforum. 2012:43(3):595-611.

28. Jarvis I, Koehoorn M, Gergel SE, van den Bosch M. Different types of urban natural environments influence various dimensions of selfreported health. Environ Res. 2020;186:109614-109614. https://doi.org/ 10.1016/j.envres.2020.109614.

29. Kabisch N, van den Bosch M, Lafortezza R. The health benefits of naturebased solutions to urbanization challenges for children and the elderlya systematic review. Environ Res. 2017;159:362-73. https://doi.org/10. 1016/j.envres.2017.08.004.

30. Nardone A, Rudolph KE, Morello-Frosch R, Casey JA. Redlines and greenspace: the relationship between historical redlining and 2010 greenspace across the United States. Environ Health Perspect. 2021;129(1):17006. https://doi.org/10.1289/EHP7495.

31. Park K, Rigolon A, Choi D-A, Lyons T, Brewer S. Transit to parks: an environmental justice study of transit access to large parks in the US West. Urban For Urban Green. 2021;60:127055.

32. Hoover FA, Lim TC. Examining privilege and power in US urban parks and open space during the double crises of antiblack racism and COVID-19. Socio Ecol Pract Res. 2020. https://doi.org/10.1007/s42532-020-00070-3.

33. Rigolon A, Németh J. What shapes uneven access to urban amenities? Thick injustice and the legacy of racial discrimination in Denver's parks. J Plan Educ Res. 2018;41(3):312-25.

34. Roberts JD. Central Park: Black bodies green spaces, white minds. Medium. 2021. https://medium.com/@ActiveRoberts/central-park-blackbodies-green-spaces-white-minds-3efebde69077.

35. Williams TG, Logan TM, Zuo CT, Liberman KD, Guikema SD. Parks and safety: a comparative study of green space access and inequity in five US cities. Landsc and Urban Plan. 2020;201:103841.

36. Zhang R, Wulff H, Duan Y, Wagner P. Associations between the physical environment and park-based physical activity: a systematic review. J Sport Health Sci. 2019;8(5):412-21.

37. McCormack GR, Rock M, Toohey AM, Hignell D. Characteristics of urban parks associated with park use and physical activity: a review of qualitative research. Health Place. 2010;16(4):712-26.

38. Huang JH, Hipp JA, Marquet O, Alberico C, Fry D, Mazak E, Lovasi GS, Robinson WR, Floyd MF. Neighborhood characteristics associated with park use and park-based physical activity among children in low-income diverse neighborhoods in New York City. Prev Med. 2020;131:105948.

39. Knapp M, Gustat J, Darensbourg R, Myers L, Johnson C. The relationship between park quality, park usage, and levels of physical activity in lowincome African American neighborhoods. Int J Environ Res Public Health. 2019. https://doi.org/10.3390/ijerph16010085.

40. Gibson S, Loukaitou-Sideris A, Mukhija V. Ensuring park equity: a California case study. J Urban Des. 2019;24(3):385-405.

41. Glanz K, Rimer BK, Viswanath K. How individuals, environments and health behaviors interact. Social cognitive theory. In: Glanz K, Rimer BK, Viswanath K, editors. Health behavior: theory, research, and practice. 5th ed. San Francisco: Jossey-Bass; 2015.

42. Richardson M, Cormack A, McRobert L, Underhill R. 30 days wild: development and evaluation of a large-scale nature engagement campaign to improve well-being. PLoS ONE. 2016;11(2):e0149777. https://doi.org/10. 1371/journal.pone.0149777.

43. Besenyi GM, Hayashi EB, Christiana RW. Prescribing physical activity in parks and nature: health care provider insights on park prescription 
programs. J Phys Act Health. 2020;17(10):958-67. https://doi.org/10.1123/ jpah.2019-0479.

44. Redding CA, Maddock JE, Rossi JS. Measurement of theoretical constructs of health behavior. Calif J Health Promot. 2006;4(1):83-101.

45. Bandura A. Self-efficacy: Toward a unifying theory of behavioral change. Psychol Rev. 1977;84(2):191-215. https://doi.org/10.1037/0033-295x.84.2. 191.

46. Tolma EL, Reininger BM, Evans A, Ureda J. Examining the theory of planned behavior and the construct of self-efficacy to predict mammography intention. Health Educ Beha. 2006;33(2):233-51. https://doi.org/10. 1177/1090198105277393.

47. Prochaska JO, Velicer WF. The transtheoretical model of health behavior change. Am J Health Promot: AJHP. 1997;12(1):38-48. https://doi.org/10. 4278/0890-1171-12.1.38.

48. Fishbein M. An integrative model for behavioral prediction and its application to health promotion. In: DiClemente RJ, Crosby RA, Kegler MC, editors. Emerging theories in health promotion practice and research. Hoboken: Jossey-Bass/Wiley; 2009. p. 215-34.

49. Ramachandran V. Encyclopedia of human behavior (PDF). San Diego: Elsevier Science Publishing Co. Inc; 1994. p. 71-81.

50. Sheeran P, Maki A, Montanaro E, Avishai-Yitshak A, Bryan A, Klein WM, Miles $E$, Rothman AJ. The impact of changing attitudes, norms, and self-efficacy on health-related intentions and behavior: a meta-analysis. Health Psychol. 2016;35(11):1178-88. https://doi.org/10.1037/hea00 00387.

51. Kelder SH, Hoelscher D, Perry CL. How individuals, environments, and health behaviors interact: Social Cognitive Theory. In: Glanz K, Rimer BK, Viswanath K, editors. Health behavior: theory, research, and practice. 5th ed. Hoboken: Jossey-Bass/Wiley; 2015. p. 159-81.

52. Netz Y, Shulamith R. Age differences in motivational orientation toward physical activity: an application of social-Cognitive Theory. J Psychol. 2010;138(1):35-48. https://doi.org/10.3200/JRLP.138.1.35-48.

53. Montano DE, Kasprzyk D. Theory of reasoned action, theory of planned behavior, and the integrated behavioral model. Health Behav Theory Res Pract. 2015;70(4):231.

54. Sheeshka J, Woolcott DM, MacKinnon NJ. Social cognitive theory as a framework to explain intentions to practice healthy eating behaviors. J Appl Soc Psychol. 1993;23(19):1547-73. https://doi.org/10.1111/j.15591816.1993.tb01047.x.

55. LaMorte WW. The Social Cognitive Theory. Boston University School of Public Health. 2019. https://sphweb.bumc.bu.edu/ott//MPH-Modules/SB/ BehavioralChangeTheories/BehavioralChangeTheories 5 html.

56. Jackson D. A sequential system for personality scale development. In: Spielberger CD, editor. Current topics in clinical and community psychology, vol. 2. New York: Academic Press; 1970. p. 61-96.

57. Comrey AL. Factor-analytic methods of scale development in personality and clinical psychology. J Consult Clin Psychol. 1988;56:754-61.

58. Boateng GO, Neilands TB, Frongillo EA, Melgar-Quiñonez HR, Young SL. Best practices for developing and validating scales for health, social, and behavioral research: a primer. Front Public Health. 2018;6:149. https://doi. org/10.3389/fpubh.2018.00149.

59. Natural England. The People and Nature Survey for England. http://publi cations.naturalengland.org.uk/publication/6382837173583872. Accessed 12 Nov 2001

60. Shanahan DF, Astell-Burt T, Barber EA, Brymer E, Cox D, Dean J, Depledge M, Fuller RA, Hartig T, Irvine KN, Jones A, Kikillus H, Lovell R, Mitchell R, Niemelä J, Nieuwenhuijsen M, Pretty J, Townsend M, van Heezik Y, Warber S, Gaston KJ. Nature-based interventions for improving health and wellbeing: the purpose, the people and the outcomes. Sports (Basel, Switzerland). 2019;7(6):141. https://doi.org/10.3390/sports7060141.

61. Maddock JE, Suess C, Smock C, Bratman G, Kellstedt D, Layton R, Kaczynski A, Gustat J, Christiana R, Horton T. Development and validation of an attitudes towards nature scale. Presented at the annual SHIFT summit, Grand Junction, CO. 2021.

62. Maddock JE. Development of social-cognitive measures for health \& nature. Presented at the annual Health \& Nature Symposium, Houston, TX. 2021.

63. Zwick WR, Velicer WF. A comparison of five rules for determining the number of components to retain. Psychol Bull. 1986;99:432-42.

64. Cattell RB. The Scree test for the number of factors. Multivar Behav Res. 1966:1:245-76
65. Lautenschlager GJ. A comparison of alternatives to conducting Monte Carlo analyses for determining parallel analysis criteria. Multivar Behav Res. 1989;24(3):265-395.

66. Horn J. A rationale and test for the number of factors in factor analysis. Psychometrika. 1965;30:179-85.

67. Hair JF, Celsi M, Ortinau DJ, Bush RP. Essentials of marketing research, vol. 2. New York: McGraw-Hill//rwin; 2010.

68. McDonald RP, Marsh HW. Choosing a multivariate model: noncentrality and goodness of fit. Psychol Bull. 1990;107:247-55.

69. Fornell C, Larcker DF. Structural equation models with unobservable variables and measurement error: algebra and statistics. J Mark Res. 1981;18:382-8.

70. Cronbach L. Coefficient alpha and the internal structure of tests. Psychometrika. 1951;16:297-334

71. Olander EK, Fletcher H, Williams S, Atkinson L, Turner A, French DP. What are the most effective techniques in changing obese individuals' physical activity self-efficacy and behaviour: a systematic review and metaanalysis. Int J Behav Nutr Phys Act. 2013;10:29. https://doi.org/10.1186/ 1479-5868-10-29.

72. Clark NM, Janevic MR. Individual theories. In: Riekert KA, Ockene JK, Pbert $L$, editors. The handbook of health behavior change. 4th ed. New York: Springer; 2014.

73. Sia A, Tam WWS, Fogel A, et al. Nature-based activities improve the wellbeing of older adults. Sci Rep. 2020;10:18178. https://doi.org/10.1038/ s41598-020-74828-w.

74. Joseph RP, Maddock JE. Observational Park-based physical activity studies: a systematic review of the literature. Prev Med. 2016;89:257-77.

75. Maddock JE. Why communities should be designing parks for older adults. The Conversation, March 15, 2017. 2017.

76. Taylor DE. Racial and ethnic differences in connectedness to nature and landscape preferences among college students. Enviro Justice. 2018;11(3):118-36.

77. Bandura A. Social foundations of thought and action: a social cognitive theory. Englewood Cliffs: Prentice-Hall; 1986.

78. Mendoza-Vasconez AS, Marquez B, Benitez TJ, et al. Psychometrics of the self-efficacy for physical activity scale among a Latina women sample. BMC Public Health. 2018;18:1097. https://doi.org/10.1186/ s12889-018-5998-0.

79. Mainvil LA, Lawson R, Horwath CC, McKenzie JE, Reeder Al. Validated scales to assess adult self-efficacy to eat fruits and vegetables. Am J Health Promot. 2009;23(3):210-7. https://doi.org/10.4278/ajhp.06122 1154.

\section{Publisher's Note}

Springer Nature remains neutral with regard to jurisdictional claims in published maps and institutional affiliations.

Ready to submit your research? Choose BMC and benefit from:

- fast, convenient online submission

- thorough peer review by experienced researchers in your field

- rapid publication on acceptance

- support for research data, including large and complex data types

- gold Open Access which fosters wider collaboration and increased citations

- maximum visibility for your research: over 100M website views per year

At BMC, research is always in progress.

Learn more biomedcentral.com/submissions 